Review

\title{
Learning under stress: A role for the neural cell adhesion molecule NCAM
}

\author{
Reto Bisaz, Lisa Conboy, Carmen Sandi * \\ Brain Mind Institute, Ecole Polytechnique Federale de Lausanne (EPFL), CH-1015 Lausanne, Switzerland
}

\section{A R T I C L E I N F O}

\section{Article history:}

Received 11 September 2008

Revised 19 October 2008

Accepted 7 November 2008

Available online 18 December 2008

\section{Keywords:}

Learning

Memory

Pavlovian conditioning

Spatial learning

Acute stress

Intrinsic stress

Extrinsic stress

Glucocorticoids

NCAM

PSA-NCAM

\begin{abstract}
A B S T R A C T
Stress is known to be a potent modulator of brain function and cognition. While prolonged and/or excessive stress generally exerts negative effects on learning and memory processes, acute stress can have differential effects on memory function depending on a number of factors (such as stress duration, stress intensity, timing and the source of the stress, as well as the learning type under study). Here, we have focused on the effects of 'acute' stress, and examined the literature attending to whether the "source of stress" is 'intrinsic' (i.e., when stress is originated by the cognitive task) or 'extrinsic' (i.e., when stress is induced by elements not related to the cognitive task). We have questioned here whether the neural cell adhesion molecule of the immunoglobulin superfamily (NCAM) contributes to the neurobiological mechanisms that translate the effects of these two different stress sources into the different behavioral and cognitive outcomes. NCAM is a cell adhesion macromolecule known to play a critical role in development and plasticity of the nervous system. NCAM and its post-translational modified form PSA-NCAM are critically involved in mechanisms of learning and memory and their expression levels are known to be highly susceptible to modulation by stress. Whereas available data are insufficient to conclude as to whether NCAM mediates extrinsic stress effects on learning and memory processes, we present systematic evidence supporting a key mediating role for both NCAM and PSA-NCAM in the facilitation of memory consolidation induced by intrinsic stress. Furthermore, NCAM is suggested to participate in some of the bidirectional effects of stress on memory processes, with its enhanced synaptic expression involved in facilitating stress actions while its reduced expression being related to impairing effects of stress on memory function.
\end{abstract}

\section{Introduction}

Stress can be regarded as an adaptive reaction which helps an organism to cope and respond to changes and to challenging situations. Such stressful situations, in which homeostasis is challenged physically and psychologically, initiate an activation of the sympathetic nervous system and the hypothalamic-pituitary-adrenal (HPA) axis, the latter resulting in increased glucocorticoid blood levels (Kim \& Diamond, 2002).

Whereas brief activation of stress responses can have beneficial consequences for the organism, such as mobilization of energy resources and suppression of immune responses, prolonged or extensive stress have a negative influence on most physiological systems (McEwen, 2002). Increasing evidence also points out that inappropriate stress responses and/or control might be associated with the development of physiological alterations and neuropsychiatric dis-

\footnotetext{
* Corresponding author. Fax: +41216939637.

E-mail address: carmen.sandi@epfl.ch (C. Sandi).
}

orders (de Kloet, Joels, \& Holsboer, 2005; Heim \& Nemeroff, 1999; Mazure, Kincare, \& Schaffer, 1995; McEwen, 2005; Sandi \& Bisaz, 2007; Wiedenmayer, 2004)

Extensive research carried out during the last decades has shown that stress is a potent modulator of brain function and cognition (de Kloet, Oitzl, \& Joels, 1999; Joels, Pu, Wiegert, Oitzl, \& Krugers, 2006; Kim \& Diamond, 2002; Kim \& Haller, 2007; McEwen, 1999; Sandi, 2004; Sandi \& Pinelo-Nava, 2007). In particular, learning and memory processes have been shown to be highly susceptible to modulation by stress. Although the common message derived form this field of stress research is that stress is detrimental for an organism, a substantial number of studies have illustrated that stress can also have a facilitating effect on learning and memory formation. In fact, a myriad of actions have been reported for stress - including impairing and facilitating effects, as well as no effects - on memory function that have prompted the need to categorize factors around both stress and memory and to dissect the nature of their interactions to specific conditions (for reviews, see de Kloet et al., 1999; Diamond, Campbell, Park, 
Halonen, \& Zoladz, 2007; Kim, Song, \& Kosten, 2006; Roozendaal, 2002, 2003; Roozendaal, Barsegyan, \& Lee, 2008; Sandi, 1998).

In a recent review (Sandi \& Pinelo-Nava, 2007), we have emphasized the importance of taking into account a number of key factors in order to progress our understanding of the impact of stress on memory function. One of those critical factors is "stress duration" and our review of the literature (Sandi \& Pinelo-Nava, 2007) showed the need to distinguish between 'acute' and 'chronic' stress situations, particularly for their demonstrated differential impact on the acquisition of information. Here, we will focus this review to the effects of 'acute' stress, since the generally deleterious effects of 'chronic' stress on learning and memory have been reviewed to a great extent in the literature (Joels et al., 2004; McEwen, 1999, 2005; Sandi, 2004).

When focusing on acute stress, one of the factors that appears to be critical is the "source of stress", which makes reference to the origin of stress with regard to the cognitive task or, in other words, to stress (or stress hormone activation) contingency to the particular information processing under study (de Kloet et al., 1999; Joels et al., 2006; Sandi, 1998). To dissect this factor into elements, we (Sandi \& Pinelo-Nava, 2007) have introduced the terminology of 'intrinsic stress', referring to the situations in which stress is originated by elements related to the cognitive task, and 'extrinsic stress', referring to those situations in which stress is originated by conditions completely unrelated to the cognitive task (i.e., the outside world) and thus generally occurring temporally dissociated from such task (i.e., either before or afterwards). Generally, intrinsic stress seems to facilitate memory consolidation processes (Joels et al., 2006; Sandi, 1998; Sandi \& Pinelo-Nava, 2007) with stress hormones (glucocorticoids, noradrenaline) reported to play a key role by exerting their actions within the same neuronal circuits that are activated by the learning experience where they can help to modulate and stabilize such neuronal circuits (Joels et al., 2006; Sandi, 1998). From an evolutionary point of view, the role of intrinsic stress would be to help the individual to recognize and remember a potentially threatening situation, allowing a faster and appropriate reaction in future encounters with a similar threat. However, when the source of stress is extrinsic, the effects seem to be quite heterogeneous, depending very much on the learning type [note that the "learning type" has also been highlighted as one of the critical factors to take into account for the understanding of the nature of stress and memory interactions (Sandi \& Pinelo-Nava, 2007)] under study (Kim \& Diamond, 2002; Roozendaal, 2002; Sandi \& Pinelo-Nava, 2007) and on the timing of the stress experience in regard to the information processing (Sandi \& Pinelo-Nava, 2007).

In addition to understanding the modulatory effects of stress on memory function, one of the challenges of the field is to decipher the neurobiological mechanisms that translate the effects of stress into the different behavioral and cognitive outcomes. Memory function is nowadays believed to involve the remodeling of neural circuits (Martin, Grimwood, \& Morris, 2000; Martin \& Morris, 2002; Morris, 2006; Morris et al., 2003) which places an important role on processes linked to synaptic mechanisms. In this context, the neural cell adhesion molecules (NCAM), a member of the immunoglobulin superfamily, that shape the formation of neuronal networks during development and is critically involved in adult synaptic plasticity, has been shown to play a critical role in memory formation (Conboy, Bisaz, Markram, \& Sandi, in press).

In this review, we will revise the related literature to question whether NCAM and its polysialylated form (PSA-NCAM) are involved in the modulatory effects that acute stress exerts in memory function. We will address this issue by separately considering situations related to intrinsic and to extrinsic stress. But before addressing these questions, we will start by giving a brief introduc- tion about the role of NCAM and PSA-NCAM in neural and synaptic plasticity.

\section{The role of NCAM on synaptic plasticity}

Neuronal CAMs of the immunoglobulin (Ig) superfamily are multidomain proteins with a key role in neural development, including axonal extension and guidance, cell migration, differentiation, survival, synaptogenesis and synaptic stabilization (Kiss \& Muller, 2001; Maness \& Schachner, 2007; Muller et al., in press; Rougon \& Hobert, 2003). Among the variety of family members, we focus here on NCAM, as in addition to its involvement in neurodevelopment, has also been largely implicated in synaptic plasticity and cognitive processes in adulthood. NCAM seems to participate in the modulation of both short-lasting plasticity at pre-existing synapses and long-lasting plasticity linked to synaptic formation and/or elimination (Fields \& Itoh, 1996; Kiss \& Muller, 2001; Schachner, 1997). Moreover, genetic epidemiological studies in humans and cumulative evidence in rodents have pointed out a critical role for this molecule in learning and emotion (for a review, see Conboy et al., in press).

\subsection{NCAM}

NCAM is expressed in the vertebrate nervous system as three main isoforms generated by alternative splicing from a single gene: NCAM-120, NCAM-140, and NCAM-180 (their names standing for their relative molecular weights) (Cunningham et al., 1987; Walmod, Kolkova, Berezin, \& Bock, 2004). Extracellularly, all isoforms bear five Ig-like modules and two fibronectin type III modules. Current knowledge about the functional roles of NCAM supports the view that interfering (i.e, blocking or impairing) with NCAM function can lead to cognitive impairments and emotional alterations (Conboy et al., in press).

Pioneer work showed that induction of long-term potentiation (LTP, regarded as an electrophysiological model of learning and memory formation) is inhibited by administration of antibodies against NCAM or of synthetic peptides able to interrupt NCAM adhesion (Lüthi, Laurent, Figurov, Muller, \& Schachner, 1994; Ronn, Bock, Linnemann, \& Jahnsen, 1995). Conversely, administration of another synthetic peptide, the NCAM-derived mimetic peptide, FG loop (FGL), which mimics NCAM activation of the fibroblast growth factor receptor 1 (FGFR1), was recently shown to effectively attenuate age-related impairment in LTP by its anti-inflammatory effect on activated microglial cells (Downer et al., in press). Deletion of the NCAM gene in NCAM knock-out (NCAM KO) mice leads to impaired LTP at CA1 and at mossy fiber synapses in CA3 hippocampal areas (Cremer et al., 1998; Muller et al., 2000). In addition, NCAM KO mice have been reported to show severe cognitive impairments and emotional alterations, including: (i) impaired spatial learning and memory (Cremer et al., 1994; Stork et al., 2000), (ii) impaired auditory and contextual fear conditioning (Senkov et al., 2006; Stork et al., 2000), (iii) impaired odor discrimination (Gheusi et al., 2000), (iv) enhanced anxiety (Cremer et al., 1994; Stork, Welzl, Cremer, and Schachner, 1997; Stork et al., 1999), (v) reduced footshock sensitization in the startle response (Plappert, Schachner, \& Pilz, 2006), (vi) enhanced exploratory behavior (Stork, Welzl, Cremer, \& Schachner, 1997; Stork et al., 1999), (vii) enhanced inter-male aggression towards an intruder (Stork et al., 1997, 2000) and (viii) increased corticosterone levels following social intruder stress (Stork et al., 1997). Moreover, these NCAM KO mice show also mild morphological alterations in the CNS, including a reduction in brain weight and size of the olfactory bulb (Cremer et al., 1994) and an altered cytoarchitecture of 
the hippocampus (Cremer, Chazal, Goridis, \& Represa, 1997; Tomasiewicz et al., 1993).

\subsection{NCAM polysialylation (PSA-NCAM)}

One important post-translational modification of NCAM is its glycosylation consisting of the addition of extended chains of the carbohydrate $\alpha 2,8$-linked polysialic acid (PSA). PSA modulates cell-cell interactions through its attachment to NCAM by reducing homo- and heterophilic NCAM adhesive activities (Cunningham, Hoffman, Rutishauser, Hemperly, \& Edelman, 1983; Johnson, Fujimoto, Rutishauser, \& Leckband, 2005; Rutishauser, 1998; Sadoul, Hirn, Deagostini-Bazin, Rougon, \& Goridis, 1983). PSA-NCAM is highly expressed during brain development and its levels gradually decrease during the early post-natal period (Angata \& Fukuda, 2003; Rutishauser, 2008). In the adult brain, high levels of PSA-NCAM remain restricted to specific regions that either retain neurogenic capacity, such as the subventricular zone and the granular cell layer of the hippocampus, or that exhibit physiological plasticity, such as regions of the hypothalamus, the entorhinal-hippocampal complex and the thalamus (Bonfanti, 2006; Gascon, Vutskits, \& Kiss, 2007; Rutishauser, 2008). PSA is synthesized by two polysialyltransferases ST8SiaII/STX (Kojima et al., 1996; Scheidegger, Sternberg, Roth, \& Lowe, 1995) and ST8SiaIV/PST (Eckhardt et al., 1995; Nakayama, Fukuda, Fredette, Ranscht, \& Fukuda, 1995). Both polysialyltransferase mRNAs are coexpressed, but they differ markedly with respect to their spatial and temporal expression patterns. While ST8SiaII/ STX is predominantly expressed in the embryo and the early post-natal brain, ST8SiaIV/PST is the form mainly expressed in the adult brain (Hildebrandt, Becker, Murau, Gerardy-Schahn, \& Rahmann, 1998).

PSA-NCAM has been implicated in cell migration, axonal regeneration, neuronal survival and synaptic plasticity (Cremer et al., 2000; Dityatev et al., 2004; Kiss, Troncoso, Djebbara, Vutskits, \& Muller, 2001). Changes in PSA expression associated with learning and memory consolidation have been observed in the dentate gyrus of the hippocampus (Doyle, Nolan, Bell, \& Regan, 1992a; Merino, Cordero, \& Sandi, 2000; Murphy, O'Connell, \& Regan, 1996; Murphy \& Regan, 1998; Sandi et al., 2003), in subregions of the amygdala complex (Markram, Lopez Fernandez, Abrous, \& Sandi, 2007b), and the entrohinal/perihinal cortices (Fox et al., 2000; O'Connell et al., 1997). Enzymatic removal of PSA, by PSA-specific endoneuraminidase (endo-N), results in complete loss of LTP and LTD induction in vitro (Muller et al., 1996), and in vivo to impaired learning and memory formation (Becker et al., 1996; Lopez-Fernandez et al., 2007; Venero et al., 2006).

Mice with a deletion of the ST8SiaIV/PST gene (ST8SiaIV/PST KO) exhibit normal development and morphological features but show a specific loss of PSA in the dentate gyrus and hilus regions as well as in the entire CA1 and CA3 subfield. This loss is accompanied by impairments of synaptic plasticity (LTP and LTD) at the Schaffer collateral CA1-synapses in the adult, but not in young animals. Interestingly synaptic plasticity in CA3 region remains unaltered in ST8SiaIV/PST knock-out mice (Eckhardt et al., 2000). This age dependent differences in synaptic plasticity is due to the fact that young ST8SiaIV/PST KO mice still express some PSA-NCAM through the second polysialyltransferase ST8SiaII/STX, which is almost not expressed in the adulthood (Hildebrandt et al., 1998). Adult ST8SiaIV/PST KO mice show also some behavioral alterations like a mild impairment in contextual fear conditioning, while auditory fear conditioning remains normal (Markram, Gerardy-Schahn, \& Sandi, 2007a; Senkov et al., 2006), and impaired spatial learning (Markram et al., 2007a). Mice with a knock-out of the other ST8SiaII/STX gene display normal synaptic plasticity (LTP) in CA1 and CA3 of the hippocampus, but have an alteration of axonal targeting in the infrapyramidal mossy fibers of the hippocampus. These morphological changes could be in part responsible for the altered behavior of these mice, such as the impaired passive avoidance learning, the hyperactivity in an open field test and reduced fear conditioning to auditory and contextual stimuli (Angata et al., 2004).

\section{Stressful learning, as a model of intrinsic stress, and NCAM}

Most of the tasks currently used to investigate learning and memory in laboratory rodents can be considered as being stressful for the animals: they are based on the application of stressful manipulations and/or stimuli to motivate animals to learn. As a consequence of their aversive nature, these stimuli elicit the activation of stress systems during training and testing (Aguilar-Valles et al., 2005; Akirav et al., 2004; Cordero, Merino, \& Sandi, 1998; Oitzl \& de Kloet, 1992). These tasks, in which learning occurs under stressful conditions, include - among others - procedures in which learning is induced by means of applying footshocks, such as in classical (fear) conditioning to a cue and/or a context, passive and active avoidance. In the water maze task, spatial learning and memory is motivated by exposing animals to a tank filled with water from which the only possible escape would be to find a hidden platform.

As indicated above, physiological stress responses elicited by learning situations can contribute to the learning-triggered processes of memory formation (de Kloet et al., 1999; Joels et al., 2006; Sandi, 1998; Sandi \& Pinelo-Nava, 2007; Wiegert, Joels, \& Krugers, 2008). The clearest and by far best illustrated example for the contribution of intrinsic stress on memory function is on the consolidation mechanisms, while its effect on acquisition and retrieval processes are still not well understood. In this subsection, we will question whether NCAM plays a role in the modulation of memory consolidation mechanisms exerted by stress. But before tackling that question, we will firstly give a brief account of the lines of evidence that have established a role for stress on memory consolidation.

First, modulating the intensity of stress experienced during the learning task (training) can have a strong impact on the strength with which the memory for the acquired information is established. For example, with regards to fear conditioning, a linear relationship between stress intensity at training (by modulating the shock intensities) and the consolidation of fear conditioning has been proposed, with higher stress intensities corresponding to stronger memories (though an asymptotic wave form would account for high-to-very-high stress intensities) (Cordero \& Sandi, 1998; Laxmi, Stork, \& Pape, 2003; Merino et al., 2000; Revest et al., 2005; Sandi \& Pinelo-Nava, 2007; Sandi et al., 2003). A similar linear relationship between stress intensities during training (by varying the water temperature) and the strength of memory formation has also been proposed for spatial learning experiences (Akirav, Sandi, \& Richter-Levin, 2001; Sandi, Loscertales, \& Guaza, 1997), while the impact of very high stressors is still uncertain since not a single study has included a wide range of stressors intensities in this sort of tasks. In any case, since high stressors during the learning task lead to stronger spatial memories than low stressors, a facilitating effect of stress can be hypothesized.

Further evidence for a role of stress on memory consolidation has been provided by numerous studies that have shown correlational and causal relationships between training-related glucocorticoid levels and the strength of the memory formed. Again a linear relationship has been reported for post-training corticosterone levels as a function of the stress intensity applied at training (and remember that, as just noted in the previous paragraph, stress 
intensity is similarly related to the strength of memory formed) (Akirav et al., 2001, 2004; Cordero et al., 1998; Merino et al., 2000; Sandi et al., 1997, 2003). Further, inhibition of either training-induced glucocorticoid secretion (through adrenalectomy or by administration of inhibitors of glucocorticoid synthesis) or of its action through central glucocorticoid receptors (via administration of specific receptor antagonists) has proved to impair memory formation for a number of tasks, including passive avoidance (Roozendaal, Williams, \& McGaugh, 1999), contextual fear conditioning (Cordero, Kruyt, Merino, \& Sandi, 2002; Cordero \& Sandi, 1998), and spatial learning in the water maze (Akirav et al., 2004; Oitzl \& de Kloet, 1992; Roozendaal, Bohus, \& McGaugh, 1996; Roozendaal \& McGaugh, 1997). Conversely, administration (systemic or central) of glucocorticoids or synthetic glucocorticoid receptor agonists either before or shortly after a particular learning task was repeatedly shown to facilitate subsequent retention for a variety of tasks, including passive avoidance (Cabib et al., 1996; Roozendaal \& McGaugh, 1996; Sandi, Rose, Mileusnic, \& Lancashire, 1995), brightness discrimination (Micheau, Destrade, \& Soumireu-Mourat, 1984), contextual fear conditioning (Cordero \& Sandi, 1998; Revest et al., 2005), eye-blink conditioning (Beylin \& Shors, 2003) and water maze learning (Akirav et al., 2004; Sandi et al., 1997).

We will question now whether NCAM is involved in these stressful learning tasks. The first experimental evidence showing a modulation of NCAM following stressful learning comes from studies on PSA-NCAM expression in rats. A transient, time-dependent increase in hippocampal NCAM polysialylation was repeatedly reported to occur around $10-12 \mathrm{~h}$ following training in passive avoidance (Doyle et al., 1992a; Fox, O'Connell, Murphy, \& Regan, 1995), water maze (Murphy, O'Connell, \& Regan, 1996; Sandi et al., 2003, 2004) and contextual fear conditioning (Sandi et al., 2003) tasks. In several studies, this was localized to a defined population of granule-like cells at the border of the granule cell layer and hilus of the rat dentate gyrus. Although a significant proportion of the polysialylated dentate neurons have been suggested to be de novo granule cell precursors (Seki \& Arai, 1993), training-induced modulations of PSA-NCAM cannot only be ascribed to neurogenesis (Foley et al., 2008; Fox, O'Connell, Murphy, \& Regan, 1995). Hippocampal upregulation of PSA-NCAM has been related to the formation of new, and the remodeling of existing, synapses between certain types of mossy fiber buttons and CA3 pyramidal cells (Seki \& Arai, 1999). Interestingly, the highest elevation of PSA-NCAM positive cells in the dentate gyrus of rats trained in water maze was found in animals showing a slower acquisition rate (Sandi et al., 2004), which also display increased anxiety and stress reactivity when confronted with learning the task (Sandi et al., 2004; Venero et al., 2004).

When NCAM polysialylation was evaluated in the dentate gyrus $12 \mathrm{~h}$ after training rats at different stressor intensities [high(1 mA), moderate- $(0.4 \mathrm{~mA})$, or low- $(0.2 \mathrm{~mA})$ shock intensities] in a contextual fear conditioning task, a differential regulation of PSA-NCAM was observed (Sandi et al., 2003). Whereas rats trained at $0.4 \mathrm{~mA}$ had increased numbers of PSA-immunopositive cells and showed also intermediate fear conditioning levels (around 50-70\% freezing) in the $12 \mathrm{~h}$ retention test, no changes in polysialylated cell frequency were observed in rats trained at a low-shock intensity $(0.2 \mathrm{~mA})$. Training at such low-shock intensity does also not induce significant fear conditioning (Sandi et al., 2003). Such findings support the view that training-induced PSA modulation participates in learning-associated synaptic remodeling (Doyle et al., 1992a; Murphy \& Regan, 1998). However, evaluation of PSA-NCAM $12 \mathrm{~h}$ after training rats at high, $1 \mathrm{~mA}$ shock intensity - a condition leading to a more robust and longer-lasting freezing response than lower shock intensities - revealed the opposite pattern; i.e., a decrease in the frequency of polysialylated neurons in the dentate gyrus (Merino et al., 2000; Sandi et al., 2003). Nevertheless, a more complete picture for the $1 \mathrm{~mA}$ high stress condition was obtained with a more detailed analysis of hippocampal PSA-NCAM expression levels analyzing separately the dorsal and ventral dentate gyrus $24 \mathrm{~h}$ after fear conditioning rats to either the context or a tone. An upregulation of PSA-NCAM expression was found in the dorsal (but not ventral) dentate gyrus after contextual (but not tone) fear conditioning. The causal implication of such upregulation in the memory formed was further confirmed by specific removal of PSA through microinfusion of endo-N that in the dorsal (but not in the ventral) hippocampus reduced freezing responses to the conditioned context (Lopez-Fernandez et al., 2007).

As for PSA-NCAM, the expression pattern of NCAM has also been shown to be influenced after training animals in stressful learning paradigms. For example, when the expression of specific NCAM isoforms was monitored in the dentate gyrus following passive avoidance training, a significant reduction of NCAM-180 was observed 3-6 $\mathrm{h}$ post-training, a time-point corresponding to the consolidation phase (Foley et al., 2000). This reduction in NCAM180 correlated with increased expression of ubiquitin C-terminal hydrolase during the same time period, suggesting that during memory consolidation NCAM undergoes regulated proteolysis by the ubiquitin dependent pathway. A reduction of total NCAM expression was also found $12 \mathrm{~h}$ after contextual fear conditioning in the hippocampus of rats that were trained at either low $(0.2 \mathrm{~mA})$, moderate $(0.4 \mathrm{~mA})$ or high $(1 \mathrm{~mA})$ shock intensities (Merino et al., 2000). In contrast, $24 \mathrm{~h}$ after training in the contextual fear conditioning paradigm, enhanced NCAM expression was only observed in rats that were trained at $1 \mathrm{~mA}$, but not at 0.2 or $0.4 \mathrm{~mA}$ (Merino et al., 2000). The same rats displayed the most pronounced freezing rate in a $24 \mathrm{~h}$ memory retention test. Thus, increased NCAM levels $24 \mathrm{~h}$ post-training in the hippocampus correlated with the enhanced memory retention observed in animals trained under the highest stress conditions.

The causal implication of such an upregulation of NCAM on the strength of the memory formed was further supported by pharmacological studies in which intracerebroventricularly administered NCAM antibodies were shown to impair spatial learning (Arami, Jucker, Schachner, \& Welzl, 1996) and passive avoidance learning (Doyle, Nolan, Bell, \& Regan, 1992b; Scholey, Rose, Zamani, Bock, \& Schachner, 1993). A direct blockade of glucocorticoid induced memory enhancement was also provoked by administration of NCAM antibodies (Sandi et al., 1995). Similarly, intracerebroventricular injections of a synthetic peptide, C3d, that interferes with NCAM homophilic binding (Cambon, Venero, Berezin, Bock, \& Sandi, 2003), either before learning or during the consolidation phase (5-8 $\mathrm{h}$ post-training) was shown to impair memory formation in various learning tasks (Cambon et al., 2003; Foley et al., 2000; Hartz, Sohoel, Berezin, Bock, \& Scheel-Kruger, 2003; Venero et al., 2006). Conversely, facilitating NCAM function, by administering the peptide FGL [which mimics the activation of the fibroblast growth factor receptor 1 (FGFR1) by NCAM] immediately after fear conditioning or water maze learning, potentiated spatial memory formation (Cambon et al., 2004). Deletion of the NCAM gene was also shown to interfere with spatial learning and memory (Bukalo et al., 2004; Cremer et al., 1994; Stork et al., 2000) and fear conditioning (Senkov et al., 2006; Stork et al., 2000).

Collectively, these findings suggest that the stress component elicited by training leads to the eventual upregulation of NCAM and PSA-NCAM which participate in the neural mechanisms involved in long-term memory storage (for a summary, see Table 1 and Fig. 1). This would fit with previous proposals in the literature of a role for NCAM in the late stages of memory consolidation, in a process that was theorized to involve the stabilization of a subset of the active synapses after an initial overproduction of synapses triggered by a strong learning experience (Doyle et al., 1992b; 
Table 1

Effect of intrinsic stress on subsequent NCAM and PSA-NCAM expression.

\begin{tabular}{|c|c|c|c|}
\hline Learning task & Short-term effects $(0-6 \mathrm{~h})$ & Medium-term effects (8-12 h) & Long-term effects (24 h) \\
\hline Passive avoidance & $\downarrow$ NCAM (DG) & $\uparrow$ PSA-NCAM (HC, DG, PFC) & $\uparrow$ PSA-NCAM (HC) \\
\hline Morris water maze & $=\operatorname{NCAM}(\mathrm{HC}, \mathrm{PFC}, \mathrm{FC})$ & $\uparrow$ PSA-NCAM (DG, EC) & $\uparrow \mathrm{NCAM}(\mathrm{HC}) \uparrow \mathrm{PSA}-\mathrm{NCAM}(\mathrm{HC})$ \\
\hline \multicolumn{4}{|l|}{ Contextual fear conditioning } \\
\hline Moderate shock intensity $(0.4 \mathrm{~mA})$ & $=$ PSA-NCAM $(\mathrm{DG})$ & $\downarrow$ NCAM (HC) $\uparrow$ PSA-NCAM (DG) & $=\mathrm{NCAM}(\mathrm{HC}) \uparrow$ PSA-NCAM (DG) \\
\hline High shock intensity ( $1 \mathrm{~mA})$ & $=$ PSA-NCAM (DG) & $\downarrow$ NCAM $(\mathrm{HC}) \downarrow$ PSA-NCAM (HC, DG) & $\uparrow \mathrm{NCAM}(\mathrm{HC}) \uparrow \mathrm{PSA}-\mathrm{NCAM}$ (DG) \\
\hline
\end{tabular}

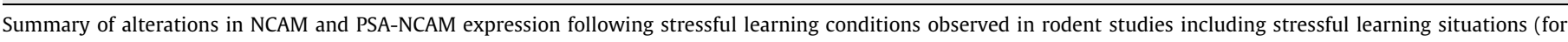
more details see main text). Abbreviations: HC, hippocampus; DG, dentate gyrus; EC, entorhinal cortex; PFC, prefrontal cortex; FC, frontal cortex.

$\uparrow$, increased expression; $\downarrow$, reduced expression; =, no changes.

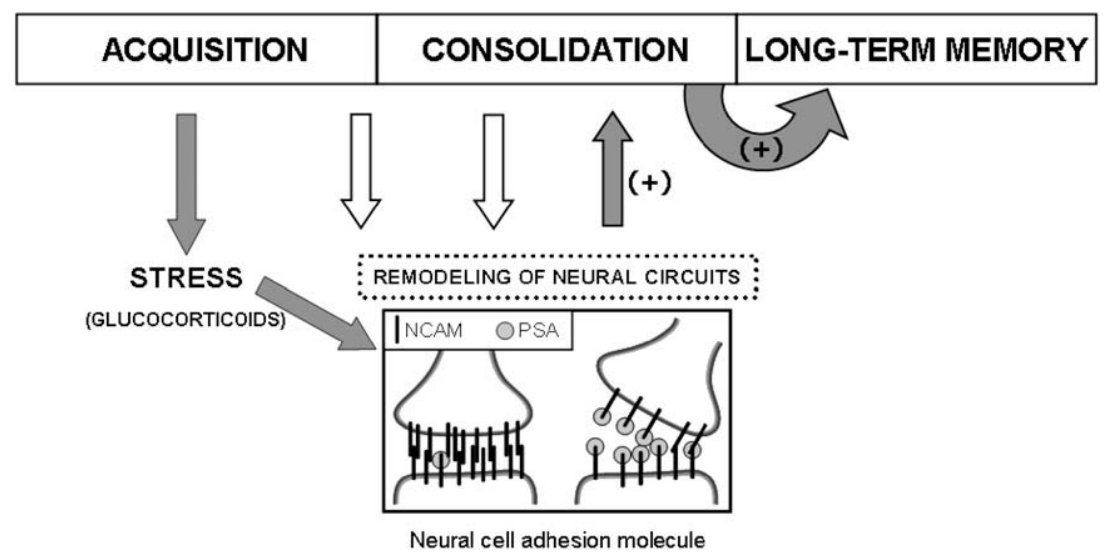

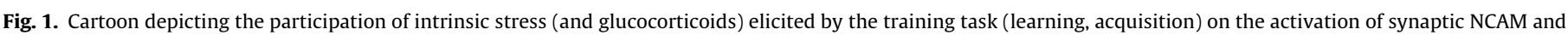

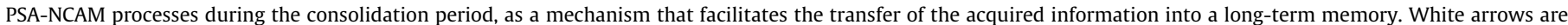

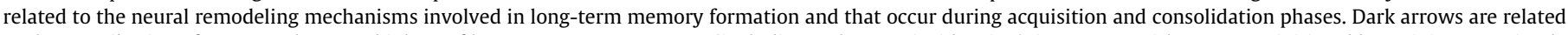

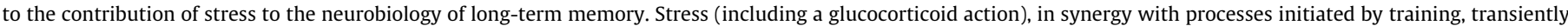

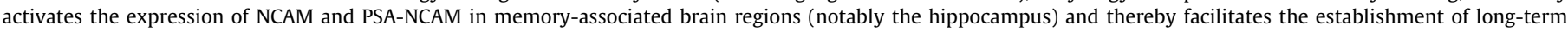
memories.

Murphy \& Regan, 1998). In agreement with such idea is the fact that a massed water maze training was not paralleled by changes in NCAM mRNA in the hippocampus when analyzed immediately after training (Venero et al., 2004), but was followed by increased synaptic NCAM expression in the hippocampus when the analysis was performed $24 \mathrm{~h}$ after water maze training (Venero et al., 2006). Such upregulation of synaptic NCAM was mainly due to isoformspecific increase of NCAM-140 and NCAM-120 expression. NCAM-120 is expressed in glial cells. Even though rising evidence supports a role for astrocytes in synaptic plasticity and potentially in learning (Schummers, Yu, \& Sur, 2008), a putative role for NCAM-120 in such processes has not yet been explored. However, substantial evidence supports a role for NCAM-140 (expressed both in neurons and glia) in plasticity and intracellular signaling (for a review, see Ditlevsen, Povlsen, Berezin, \& Bock, 2008). For example, a constitutive association has been found between NCAM-140 and Fyn (a member of the Src family of non-receptor tyrosine kinases highly expressed in neural tissue) (Ditlevsen et al., 2008). Interestingly, Fyn activation leads to recruitment and activation of the focal adhesion kinase (FAK), which is another non-receptor tyrosine kinase. FAK has been shown to be coimmunoprecipitated with NCAM and Fyn in neurons and to be phosphorylated upon NCAM stimulation (Beggs, Baragona, Hemperly, \& Maness, 1997). Prybylowski et al. (2005) implicated Fyn in regulating internalization and synaptic localization of NR2B-containing NMDA receptors. The association of NCAM-140 with Fyn and the activation of Fyn followed by recruitment and activation of FAK upon NCAM stimulation represent a way in which NCAM-140 itself can activate intracellular signaling pathways leading to neurite outgrowth on NCAM stimulation. Interestingly, the importance of NCAM-140 in memory formation is further supported by a study (Touyarot, Venero, \& Sandi, 2004) showing that NCAM-140 was the NCAM isoform specifically reduced in rats submitted to a chronic stress procedure that simultaneously impaired spatial memory.

\section{Glucocorticoids, as mediators of intrinsic stress effects on learning, and NCAM}

As stated above, glucocorticoids interacting with glucocorticoid receptors have been implicated as key mediators of the effects of stressful learning on long-term memory facilitation by modulation of the consolidation processes. Systemic injection of corticosterone (at a dose that mimics plasma steroid concentrations produced by substantial stress, and were shown to facilitate certain types of memory when injected immediately after submitting animals to weak training) induced an increased expression of NCAM 8 and $24 \mathrm{~h}$ post-injection in the frontal cortex, whereas no changes were found in the hippocampus and the hypothalamus (Sandi \& Loscertales, 1999). Given that hippocampal cells present a high density of mineralocorticoid and glucocorticoid receptors and hippocampal dependent learning is facilitated by post-training corticosterone administration, it is striking that no changes in NCAM expression were found in the hippocampus. However, this might indicate that glucocorticoids need to synergize with training-induced activity and biochemical cascades in relevant neural pathways within the hippocampus (and probably other brain regions). Experiments involving weak training protocols and corticosterone injections 
or, alternatively, strong training conditions and glucocorticoid synthesis inhibitors or glucocorticoid receptor antagonists, would be needed to establish whether stressful learning-induced modulations of hippocampal NCAM expression can be causally modulated by manipulating glucocorticoid actions.

Interestingly, recent work implicated the MAPK signaling cascade in the facilitation of contextual fear conditioning induced by post-training intrahippocampal corticosterone administration (Revest et al., 2005). This is relevant in the context of some of the mechanisms of action linked to NCAM signaling cascades. It has been shown in vitro that the FGL NCAM mimetic peptide, which potentiates both contextual fear conditioning and water maze training when given immediately after training (Cambon et al., 2004), activates - beside other signaling cascades - the MAPK intracellular signaling pathway (Neiiendam et al., 2004). Thus, NCAM might be implicated in the glucocorticoid receptor-mediated activation of the MAPK cascade occurring during memory consolidation for (hippocampus-dependent) stressful learning experiences. Gene expression studies have confirmed NCAM among the corticosterone-responsive hippocampal genes that are regulated through a GR action (Datson, van der Perk, de Kloet, \& Vreugdenhil, 2001).

\section{Extrinsic stress and NCAM}

Extrinsic stress is stress that occurs 'outside the context' of the learning task (de Kloet et al., 1999; Sandi \& Pinelo-Nava, 2007). Contrary to the facilitating influence of learning-induced activation of the stress system (intrinsic stress) on memory consolidation, acute exposure to extrinsic stress can have beneficial or deleterious effects on learning and memory, depending on the type of learning and the timing at which the stressor is applied with regard to the memory phase. In our recent literature review (Sandi \& PineloNava, 2007) we reasoned two main conclusions from available data in the literature as to how acute extrinsic stress affects learning: (1) pre-training stress tends to facilitate Pavlovian conditioning processes, while (2) stress given before retention tests for explicit-like types or information (e.g., spatial learning) tends to interfere with the memory retrieval. We will now expand briefly on the work that led to these conclusions and then question the available evidence regarding the involvement of NCAM on these stress regulatory processes.

As to the effects of acute extrinsic stress on the acquisition of Pavlovian conditioning, substantial work has been performed with the eyeblink conditioning (Shors, 2004). In this task, the animal learns to associate a conditioned stimulus (CS; frequently a tone) with an unconditioned stimulus (US; frequently a periorbital shock to the eyelid). By itself, the US leads to an eye blinking (unconditioned response, $\mathrm{CR}$ ). By exposing rats to frequent pairing of the tone and the shock, they learn over time to associate both stimuli and to respond to the tone by eye blinking, before or even in the absence of the shock. Pre-training application of an acute inescapable stressor consisting on a coupling of restraint and intermittent tail-shocks has been repeatedly shown to enhance this type of associative learning (Servatius \& Shors, 1994; Shors \& Servatius, 1997; Shors, Weiss, \& Thompson, 1992). Learning is enhanced if training occurs immediately after the stressor or even $24 \mathrm{~h}$ later suggesting that its effects are rapid and long lasting. Beside the facilitating effect of pre-training stress exposure on classical eyeblink conditioning, the acquisition of fear conditioning has also been shown to be highly susceptible by prior stress exposure. For instance, acute exposure to a single restrain stress session facilitated subsequent auditory and contextual fear conditioning in rats and mice (Cordero et al., 2005; Radulovic, Ruhmann, Liepold, \& Spiess, 1999; Rodriguez Manzanares, Isoardi, Carrer, \& Molina, 2005).
The molecular mechanisms governing this facilitation are unclear and evidence linking this particular type of stressors with the expression of NCAM or PSA-NCAM is missing. However, circumstantial evidence suggests their potential implication and we will expose it here without implying that any direct proof for a link between NCAM and eyeblink conditioning actually exist. Thus, eyeblink conditioning increases neuronal activity and spine density in hippocampal CA1 region (Berger, Rinaldi, Weisz, \& Thompson, 1983; Leuner, Falduto, \& Shors, 2003; McEchron \& Disterhoft, 1999). Interestingly, the same acute extrinsic stress that facilitates eyeblink conditioning is able, by itself, of increasing both hippocampal dendritic spine density (Shors, Chua, \& Falduto, 2001) and excitability of CA1 pyramidal cells (Weiss, Sametsky, Sasse, Spiess, \& Disterhoft, 2005) in male rodents. Furthermore, rapid spinogenesis of pyramidal neurons is induced by a single application of the synthetic glucocorticoid dexamethasone (Komatsuzaki et al., 2005) and NCAM and PSA-NCAM are known to be critically involved in regulating spinogenesis and synapatogenesis (Dityatev et al., 2004; Muller et al., in press), as well as synaptic activity (Bukalo et al., 2004; Cremer et al., 1998; Lüthi et al., 1994; Muller et al., 1996; Ronn et al., 1995; Senkov et al., 2006). Moreover, the basolateral amygdala (BLA) has been implicated in the facilitation of eyeblink conditioning induced by prior stress (Shors \& Mathew, 1998; Waddell, Bangasser, \& Shors, 2008) and recent evidence indicates that PSA-NCAM in this amygdaloid nucleus is highly responsive to different stress schedules (Cordero et al., 2005; Markram et al., 2007b). However, the potential implication of PSA-NCAM (and NCAM) in the amygdala on stress effects on conditioning processes still remains to be tested.

More information is available with regards to the regulation of NCAM under conditions related to disrupting effects of extrinsic stress on the retrieval of previously acquired information. Such disruptive effects have been shown to occur when stress is applied $30 \mathrm{~min}$ before a retention session, $24 \mathrm{~h}$ after training animals in the water maze (de Quervain, Roozendaal, \& McGaugh, 1998) and when it is applied during the $30 \mathrm{~min}$ before testing in a radial arm water maze under a protocol in which learning was applied on the same day just before both, stress and retention testing (Diamond, Park, Heman, \& Rose, 1999; Sandi et al., 2005; Woodson, Macintosh, Fleshner, \& Diamond, 2003). Glucocorticoids were implicated in the impairing effect of stress, with increasing corticosterone levels being necessary and sufficient (though interacting with noradrenergic mechanisms in the basolateral amygdala) to impair retrieval when animals were tested $24 \mathrm{~h}$ after training (de Quervain et al., 1998; Roozendaal, Griffith, Buranday, De Quervain, \& McGaugh, 2003; Roozendaal, Hahn, Nathan, de Quervain, \& McGaugh, 2004). Glucocorticoids have also been implicated, although by themselves shown not to be sufficient, to block retrieval when the effects of stress on retrieval were examined immediately after having trained rats in the radial arm water maze (Woodson et al., 2003).

A modulation in hippocampal NCAM expression has been associated with a predator stress induced deficit in the retrieval of spatial information acquired in the radial arm water maze (Sandi et al., 2005). Specifically, a 30 min predator stress exposure (cat exposure) immediately after training induced a marked suppression of the synaptic NCAM-180 isoform in the hippocampus. Moreover, predator stress also induced a more global reduction of NCAM levels in the prefrontal cortex, but had no effect on NCAM levels in the amygdala or cerebellum (Sandi et al., 2005). However, one should be cautious as to the conclusions that can be extracted about the potential functional meaning of such regulation. Even though in this study, cat exposure took place throughout a 30 -min period between the acquisition and retrieval phases (testing took place 30 min post-training), a subsequent paper showed that the same stress manipulation (i.e., cat exposure given immediately after 
training), in addition to short-term memory, it impaired as well short-term memory processes involved in memory consolidation and retrieval (Park, Zoladz, Conrad, Fleshner, \& Diamond, 2008). Therefore, at this stage, it is not possible to ascertain whether NCAM reductions observed immediately after predator stress would be linked to stress-induced impairment of consolidation, retrieval or to both processes. In fact, given the well known involvement of NCAM in long-term memory formation (see above), it is plausible that the strong reduction of NCAM levels found in the hippocampus shortly after predator stress contributes, at least, to impaired long-term consolidation of spatial memory. Whatever type of 'cognitive' processes is involved, it is interesting to note that a recent work showed that an antidepressant treatment resulting in upregulation of NCAM expression was protective against the negative effect of predator stress on spatial memory retrieval (Conboy et al., 2008).

An important issue to address is the promptness at which NCAM changes took place after exposure to predator stress. Whereas processes leading to enhanced NCAM expression would require a time-lapse of hours to allow for protein synthesis to take place, the rapid time course of NCAM synaptic downregulation observed after cat exposure can be sustained by fast mechanisms, including its internalization from the cellular membrane followed by either degradation or by redistribution among cellular compartments (Bailey, Chen, Keller, \& Kandel, 1992; Foley et al., 2000; Mayford, Barzilai, Keller, Schacher, \& Kandel, 1992), and/or its extracellular release (Fazeli, Breen, Errington, \& Bliss, 1994). Rapid NCAM release and degradation have been reported to be induced by stimulation of glutamatergic receptors (Endo et al., 1999; Hoffman, Larson, Bahr, \& Lynch, 1998) and the induction of hippocampal LTP (Fazeli et al., 1994).

The relevance of these findings for the understanding of how extrinsic stress can interfere with spatial memory retrieval can only be indirectly discussed since so far no intervention has just addressed the effects of interfering with NCAM or PSA-NCAM function on retrieval of information. Most of the evidence comes from work done with $\mathrm{C} 3 \mathrm{~d}$, the mimetic peptide that disrupts NCAM function related to homophilic adhesion. Following intracerebroventricular injection, C3d was able to inhibit long-term retrieval of previously acquired information while having no effect on the initial phases of spatial learning in the water maze (Venero et al., 2006). However, the fact that the peptide had been injected pretraining does not allow excluding potential effects on memory consolidation. In fact, when injected during the post-training period, the C3d peptide was also shown to interfere with the eventual retention of contextual fear conditioning (Cambon et al., 2003) and passive avoidance learning (Foley et al., 2000). These findings strongly support a key role of hippocampal NCAM downregulation in the impairing effects induced by acute extrinsic stress on the consolidation and/or retrieval of spatial information, but they do not allow to draw any conclusion as to whether or not NCAM interference would disrupt recall or not. On the other hand, no evidence is currently available as to an implication of PSA-NCAM on these processes. However, Pham, Nacher, Hof, and McEwen (2003) showed that a single acute restraint session did not modify PSANCAM levels in the hippocampal dentate gyrus.

\section{Conclusions}

Drawing from a vast pool of research, we have analyzed here the literature related to the neurobiological contribution of NCAM and PSA-NCAM on learning and memory processes under situations involving acute intrinsic or extrinsic stress. The reviewed evidence leads us to suggest that NCAM and PSA-NCAM are involved in the memory facilitation induced by intrinsic stress (Fig. 1). As for extrinsic stress, further work is needed before any conclusion can be drawn about a potential role of this adhesion molecule. Whereas data relating NCAM to acute stress-induced facilitation of conditioning processes is still lacking, the experimental designs followed so far to investigate NCAM contribution to extrinsic stress effects on retrieval processes do not allow distinguishing between its potential associations with retrieval and/or consolidation processes. In any case, what this latter line of research indicates is that extrinsic stress applied after training and impairing recall (including to impaired short-term memory, retrieval and consolidation of long-term memory) would have the converse effect to that observed under intrinsic stress conditions leading to facilitated memory; i.e., the inhibition of NCAM synaptic expression in neural pathways critically involved in information processing and recall, such as the hippocampus and prefrontal cortex. In summary, we propose that NCAM and PSA-NCAM are important regulators of the effects of acute intrinsic stress on memory consolidation. Furthermore, this review highlights NCAM as one of the molecules potentially involved in some of the bidirectional effects of stress on memory processes, with its enhanced synaptic expression involved in facilitating stress actions while its reduced expression being related to impairing effects of stress on mnemonic processes.

\section{Acknowledgments}

This work has been supported by grants from the EU (FP6-2003LIFESCIHEALTH-II-512012, PROMEMORIA; and FP7-HEALTH-F2M2008-201600, MemStick), the Swiss National Science Foundation (3100A0-108102 and 310000-120791) and intramural funding from the EPFL. The authors thank previous and current coworkers for their original contributions.

\section{References}

Aguilar-Valles, A., Sanchez, E., de Gortari, P., Balderas, I., Ramirez-Amaya, V., Bermudez-Rattoni, F., et al. (2005). Analysis of the stress response in rats trained in the water-maze: Differential expression of corticotropin-releasing hormone, CRH-R1, glucocorticoid receptors and brain-derived neurotrophic factor in limbic regions. Neuroendocrinology, 82, 306-319.

Akirav, I., Kozenicky, M., Tal, D., Sandi, C., Venero, C., \& Richter-Levin, G. (2004). A facilitative role for corticosterone in the acquisition of a spatial task under moderate stress. Learning \& Memory, 11, 188-195.

Akirav, I., Sandi, C., \& Richter-Levin, G. (2001). Differential activation of hippocampus and amygdala following spatial learning under stress. European Journal of Neuroscience, 14, 719-725.

Angata, K., \& Fukuda, M. (2003). Polysialyltransferases: Major players in polysialic acid synthesis on the neural cell adhesion molecule. Biochimie, 85, 195-206.

Angata, K., Long, J. M., Bukalo, O., Lee, W., Dityatev, A., Wynshaw-Boris, A., et al. (2004). Sialyltransferase ST8Sia-II assembles a subset of polysialic acid that directs hippocampal axonal targeting and promotes fear behavior. Journal of Biological Chemistry, 279, 32603-32613.

Arami, S., Jucker, M., Schachner, M., \& Welzl, H. (1996). The effect of continuous intraventricular infusion of L1 and NCAM antibodies on spatial learning in rats. Behavioural Brain Research, 81, 81-87.

Bailey, C. H., Chen, M., Keller, F., \& Kandel, E. R. (1992). Serotonin-mediated endocytosis of apCAM: An early step of learning-related synaptic growth in Aplysia. Science, 256, 645-649.

Becker, C. G., Artola, A., Gerardy-Schahn, R., Becker, T., Welzl, H., \& Schachner, M. (1996). The polysialic acid modification of the neural cell adhesion molecule is involved in spatial learning and hippocampal long-term potentiation. Journal of Neuroscience Research, 45, 143-152.

Beggs, H. E., Baragona, S. C., Hemperly, J. J., \& Maness, P. F. (1997). NCAM140 interacts with the focal adhesion kinase p125(fak) and the SRC-related tyrosine kinase p59(fyn). Journal of Biological Chemistry, 272, 8310-8319.

Berger, T. W., Rinaldi, P. C., Weisz, D. J., \& Thompson, R. F. (1983). Single-unit analysis of different hippocampal cell types during classical conditioning of rabbit nictitating membrane response. Journal of Neurophysiology, 50 , 1197-1219.

Beylin, A. V., \& Shors, T. J. (2003). Glucocorticoids are necessary for enhancing the acquisition of associative memories after acute stressful experience. Hormones and Behavior, 43, 124-131.

Bonfanti, L. (2006). PSA-NCAM in mammalian structural plasticity and neurogenesis. Progress in Neurobiology, 80, 129-164.

Bukalo, O., Fentrop, N., Lee, A. Y., Salmen, B., Law, J. W., Wotjak, C. T., et al. (2004) Conditional ablation of the neural cell adhesion molecule reduces precision of 
spatial learning, long-term potentiation, and depression in the CA1 subfield of mouse hippocampus. Journal of Neuroscience, 24, 1565-1577.

Cabib, S., Castellano, C., Patacchioli, F. R., Cigliana, G., Angelucci, L., \& Puglisi-Allegra, S. (1996). Opposite strain-dependent effects of post-training corticosterone in a passive avoidance task in mice: Role of dopamine. Brain Research, 729, 110-118.

Cambon, K., Hansen, S. M., Venero, C., Herrero, A. I., Skibo, G., Berezin, V., et al. (2004). A synthetic neural cell adhesion molecule mimetic peptide promotes synaptogenesis, enhances presynaptic function, and facilitates memory consolidation. Journal of Neuroscience, 24, 4197-4204.

Cambon, K., Venero, C., Berezin, V., Bock, E., \& Sandi, C. (2003). Post-training administration of a synthetic peptide ligand of the neural cell adhesion molecule, C3d, attenuates long-term expression of contextual fear conditioning. Neuroscience, 122, 183-191.

Conboy, L., Bisaz, R., Markram, K., \& Sandi, C. (in press). Role of NCAM in emotion and learning. Neurochemical Research.

Conboy, L., Tanrikut, C., Zoladz, P. R., Campbell, A. M., Park, C. R., Gabriel, C., et al. (2008). The antidepressant agomelatine blocks the adverse effects of stress on memory and enables spatial learning to rapidly increase neural cell adhesion molecule (NCAM) expression in the hippocampus of rats. International Journal of Neuropsychopharmacology, 1-13.

Cordero, M. I., Kruyt, N. D., Merino, J. J., \& Sandi, C. (2002). Glucocorticoid involvement in memory formation in a rat model for traumatic memory. Stress, 5, 73-79.

Cordero, M. I., Merino, J. J., \& Sandi, C. (1998). Correlational relationship between shock intensity and corticosterone secretion on the establishment and subsequent expression of contextual fear conditioning. Behavioral Neurosciences, 112, 885-891.

Cordero, M. I., Rodriguez, J. J., Davies, H. A., Peddie, C. J., Sandi, C., \& Stewart, M. G. (2005). Chronic restraint stress down-regulates amygdaloid expression of polysialylated neural cell adhesion molecule. Neuroscience, 133, 903-910.

Cordero, M. I., \& Sandi, C. (1998). A role for brain glucocorticoid receptors in contextual fear conditioning: Dependence upon training intensity. Brain Research, 786, 11-17.

Cremer, H., Chazal, G., Carleton, A., Goridis, C., Vincent, J. D., \& Lledo, P. M. (1998). Long-term but not short-term plasticity at mossy fiber synapses is impaired in neural cell adhesion molecule-deficient mice. Proceedings of the National Academy of Sciences of the United States of America, 95, 13242-13247.

Cremer, H., Chazal, G., Goridis, C., \& Represa, A. (1997). NCAM is essential for axonal growth and fasciculation in the hippocampus. Molecular and Cellular Neuroscience, 8, 323-335.

Cremer, H., Chazal, G., Lledo, P. M., Rougon, G., Montaron, M. F., Mayo, W., et al. (2000). PSA-NCAM: An important regulator of hippocampal plasticity. International Journal of Developmental Neuroscience, 18, 213-220.

Cremer, H., Lange, R., Christoph, A., Plomann, M., Vopper, G., Roes, J., et al. (1994). Inactivation of the N-CAM gene in mice results in size reduction of the olfactory bulb and deficits in spatial learning. Nature, 367, 455-459.

Cunningham, B. A., Hemperly, J. J., Murray, B. A., Prediger, E. A., Brackenbury, R., \& Edelman, G. M. (1987). Neural cell adhesion molecule: Structure, immunoglobulin-like domains, cell surface modulation, and alternative RNA splicing. Science, 236, 799-806.

Cunningham, B. A., Hoffman, S., Rutishauser, U., Hemperly, J. J., \& Edelman, G. M. (1983). Molecular topography of the neural cell adhesion molecule N-CAM: Surface orientation and location of sialic acid-rich and binding regions. Proceedings of the National Academy of Sciences of the United States of America, 80, 3116-3120.

Datson, N. A., van der Perk, J., de Kloet, E. R., \& Vreugdenhil, E. (2001). Identification of corticosteroid-responsive genes in rat hippocampus using serial analysis of gene expression. European Journal of Neuroscience, 14, 675-689.

de Kloet, E. R., Joels, M., \& Holsboer, F. (2005). Stress and the brain: From adaptation to disease. Nature Reviews Neuroscience, 6, 463-475.

de Kloet, E. R., Oitzl, M. S., \& Joels, M. (1999). Stress and cognition: Are corticosteroids good or bad guys? Trends in Neuroscience, 22, 422-426.

de Quervain, D. J., Roozendaal, B., \& McGaugh, J. L. (1998). Stress and glucocorticoids impair retrieval of long-term spatial memory. Nature, 394, 787-790.

Diamond, D. M., Campbell, A. M., Park, C. R., Halonen, J., \& Zoladz, P. R. (2007). The temporal dynamics model of emotional memory processing: A synthesis on the neurobiological basis of stress-induced amnesia, flashbulb and traumatic memories, and the Yerkes-Dodson law. Neural Plasticity, 2007, 60803.

Diamond, D. M., Park, C. R., Heman, K. L., \& Rose, G. M. (1999). Exposing rats to a predator impairs spatial working memory in the radial arm water maze. Hippocampus, 9, 542-552.

Ditlevsen, D. K., Povlsen, G. K., Berezin, V., \& Bock, E. (2008). NCAM-induced intracellular signaling revisited. Journal of Neuroscience Research, 86, 727-743.

Dityatev, A., Dityateva, G., Sytnyk, V., Delling, M., Toni, N., Nikonenko, I., et al. (2004). Polysialylated neural cell adhesion molecule promotes remodeling and formation of hippocampal synapses. Journal of Neuroscience, 24, 9372-9382.

Downer, E. J., Cowley, T. R., Lyons, A., Mills, K. H., Berezin, V., Bock, E., et al. (in press). A novel anti-inflammatory role of NCAM-derived mimetic peptide FGL Neurobiological Aging.

Doyle, E., Nolan, P. M., Bell, R., \& Regan, C. M. (1992a). Hippocampal NCAM180 transiently increases sialylation during the acquisition and consolidation of a passive avoidance response in the adult rat. Journal of Neuroscience Research, 31, 513-523.

Doyle, E., Nolan, P. M., Bell, R., \& Regan, C. M. (1992b). Intraventricular infusions of anti-neural cell adhesion molecules in a discrete posttraining period impair consolidation of a passive avoidance response in the rat. Journal of Neurochemistry, 59, 1570-1573.

Eckhardt, M., Bukalo, O., Chazal, G., Wang, L., Goridis, C., Schachner, M., et al. (2000) Mice deficient in the polysialyltransferase ST8SiaIV/PST-1 allow discrimination of the roles of neural cell adhesion molecule protein and polysialic acid in neural development and synaptic plasticity. Journal of Neuroscience, 20, 5234-5244

Eckhardt, M., Muhlenhoff, M., Bethe, A., Koopman, J., Frosch, M., \& Gerardy-Schahn, R. (1995). Molecular characterization of eukaryotic polysialyltransferase-1. Nature, 373, 715-718.

Endo, A., Nagai, N., Urano, T., Takada, Y., Hashimoto, K., \& Takada, A. (1999). Proteolysis of neuronal cell adhesion molecule by the tissue plasminogen activator-plasmin system after kainate injection in the mouse hippocampus. Neuroscience Research, 33, 1-8.

Fazeli, M. S., Breen, K., Errington, M. L., \& Bliss, T. V. (1994). Increase in extracellular NCAM and amyloid precursor protein following induction of long-term potentiation in the dentate gyrus of anaesthetized rats. Neuroscience Letters, 169, 77-80.

Fields, R. D., \& Itoh, K. (1996). Neural cell adhesion molecules in activity-dependent development and synaptic plasticity. Trends in Neuroscience, 19, 473-480.

Foley, A. G., Hartz, B. P., Gallagher, H. C., Ronn, L. C., Berezin, V., Bock, E., et al. (2000). A synthetic peptide ligand of neural cell adhesion molecule (NCAM) IgI domain prevents NCAM internalization and disrupts passive avoidance learning. Journal of Neurochemistry, 74, 2607-2613.

Foley, A. G., Hirst, W. D., Gallagher, H. C., Barry, C., Hagan, J. J., Upton, N., et al. (2008). The selective 5-HT6 receptor antagonists SB-271046 and SB-399885 potentiate NCAM PSA immunolabeling of dentate granule cells, but not neurogenesis, in the hippocampal formation of mature Wistar rats. Neuropharmacology, 54, 1166-1174.

Fox, G. B., Fichera, G., Barry, T., O'Connell, A. W., Gallagher, H. C., Murphy, K. J., et al. (2000). Consolidation of passive avoidance learning is associated with transient increases of polysialylated neurons in layer II of the rat medial temporal cortex Journal of Neurobiology, 45, 135-141.

Fox, G. B., O'Connell, A. W., Murphy, K. J., \& Regan, C. M. (1995). Memory consolidation induces a transient and time-dependent increase in the frequency of neural cell adhesion molecule polysialylated cells in the adult rat hippocampus. Journal of Neurochemistry, 65, 2796-2799.

Gascon, E., Vutskits, L., \& Kiss, J. Z. (2007). Polysialic acid-neural cell adhesion molecule in brain plasticity: From synapses to integration of new neurons. Brain Research Reviews, 56, 101-118.

Gheusi, G., Cremer, H., McLean, H., Chazal, G., Vincent, J. D., \& Lledo, P. M. (2000). Importance of newly generated neurons in the adult olfactory bulb for odor discrimination. Proceedings of the National Academy of Sciences of the United States of America, 97, 1823-1828.

Hartz, B. P., Sohoel, A., Berezin, V., Bock, E., \& Scheel-Kruger, J. (2003). A synthetic peptide ligand of NCAM affects exploratory behavior and memory in rodents. Pharmacology and Biochemical Behavior, 75, 861-867.

Heim, C., \& Nemeroff, C. B. (1999). The impact of early adverse experiences on brain systems involved in the pathophysiology of anxiety and affective disorders. Biological Psychiatry, 46, 1509-1522.

Hildebrandt, H., Becker, C., Murau, M., Gerardy-Schahn, R., \& Rahmann, H. (1998) Heterogeneous expression of the polysialyltransferases ST8Sia II and ST8Sia IV during postnatal rat brain development. Journal of Neurochemistry, 71 2339-2348.

Hoffman, K. B., Larson, J., Bahr, B. A., \& Lynch, G. (1998). Activation of NMDA receptors stimulates extracellular proteolysis of cell adhesion molecules in hippocampus. Brain Research, 811, 152-155.

Joels, M., Karst, H., Alfarez, D., Heine, V. M., Qin, Y., van Riel, E., et al. (2004). Effects of chronic stress on structure and cell function in rat hippocampus and hypothalamus. Stress, 7, 221-231.

Joels, M., Pu, Z., Wiegert, O., Oitzl, M. S., \& Krugers, H. J. (2006). Learning under stress: How does it work? Trends in Cognitive Science, 10, 152-158.

Johnson, C. P., Fujimoto, I., Rutishauser, U., \& Leckband, D. E. (2005). Direct evidence that neural cell adhesion molecule (NCAM) polysialylation increases intermembrane repulsion and abrogates adhesion. Journal of Biological Chemistry, 280, 137-145.

Kim, J. J., \& Diamond, D. M. (2002). The stressed hippocampus, synaptic plasticity and lost memories. Nature Reviews Neuroscience, 3, 453-462.

Kim, J. J., \& Haller, J. (2007). Glucocorticoid hyper- and hypofunction: Stress effects on cognition and aggression. Annals of the New York Academy of Sciences, 1113 291-303.

Kim, J. J., Song, E. Y., \& Kosten, T. A. (2006). Stress effects in the hippocampus: Synaptic plasticity and memory. Stress, 9, 1-11.

Kiss, J. Z., \& Muller, D. (2001). Contribution of the neural cell adhesion molecule to neuronal and synaptic plasticity. Reviews of Neuroscience, 12, 297-310.

Kiss, J. Z., Troncoso, E., Djebbara, Z., Vutskits, L., \& Muller, D. (2001). The role of neural cell adhesion molecules in plasticity and repair. Brain Research. Brain Research Reviews, 36, 175-184.

Kojima, N., Kono, M., Yoshida, Y., Tachida, Y., Nakafuku, M., \& Tsuji, S. (1996). Biosynthesis and expression of polysialic acid on the neural cell adhesion molecule is predominantly directed by ST8Sia II/STX during in vitro neuronal differentiation. Journal of Biological Chemistry, 271, 22058-22062.

Komatsuzaki, Y., Murakami, G., Tsurugizawa, T., Mukai, H., Tanabe, N., Mitsuhashi, K., et al. (2005). Rapid spinogenesis of pyramidal neurons induced by activation of glucocorticoid receptors in adult male rat hippocampus. Biochemical Biophysics Research Communication, 335, 1002-1007. 
Laxmi, T. R., Stork, O., \& Pape, H. C. (2003). Generalisation of conditioned fear and its behavioural expression in mice. Behavioural Brain Research, 145, 89-98.

Leuner, B., Falduto, J., \& Shors, T. J. (2003). Associative memory formation increases the observation of dendritic spines in the hippocampus. Journal of Neuroscience, 23, 659-665.

Lopez-Fernandez, M. A., Montaron, M. F., Varea, E., Rougon, G., Venero, C., Abrous, D. N., et al. (2007). Upregulation of polysialylated neural cell adhesion molecule in the dorsal hippocampus after contextual fear conditioning is involved in longterm memory formation. Journal of Neuroscience, 27, 4552-4561.

Lüthi, A., Laurent, J. P., Figurov, A., Muller, D., \& Schachner, M. (1994). Hippocampal long-term potentiation and neural cell adhesion molecules L1 and NCAM. Nature, 372, 777-779.

Maness, P. F., \& Schachner, M. (2007). Neural recognition molecules of the immunoglobulin superfamily: Signaling transducers of axon guidance and neuronal migration. Nature Neuroscience, 10, 19-26.

Markram, K., Gerardy-Schahn, R., \& Sandi, C. (2007a). Selective learning and memory impairments in mice deficient for polysialylated NCAM in adulthood. Neuroscience, 144, 788-796.

Markram, K., Lopez Fernandez, M. A., Abrous, D. N., \& Sandi, C. (2007b). Amygdala upregulation of NCAM polysialylation induced by auditory fear conditioning is not required for memory formation, but plays a role in fear extinction. Neurobiology of Learning and Memory, 87, 573-582.

Martin, S. J., Grimwood, P. D., \& Morris, R. G. (2000). Synaptic plasticity and memory: An evaluation of the hypothesis. Annual Reviews of Neuroscience, 23, 649-711.

Martin, S. J., \& Morris, R. G. (2002). New life in an old idea: The synaptic plasticity and memory hypothesis revisited. Hippocampus, 12, 609-636.

Mayford, M., Barzilai, A., Keller, F., Schacher, S., \& Kandel, E. R. (1992). Modulation of an NCAM-related adhesion molecule with long-term synaptic plasticity in Aplysia. Science, 256, 638-644.

Mazure, C. M., Kincare, P., \& Schaffer, C. E. (1995). DSM-III-R Axis IV: Clinician reliability and comparability to patients' reports of stressor severity. Psychiatry, $58,56-64$.

McEchron, M. D., \& Disterhoft, J. F. (1999). Hippocampal encoding of non-spatial trace conditioning. Hippocampus, 9, 385-396.

McEwen, B. S. (1999). Stress and hippocampal plasticity. Annual Reviews of Neuroscience, 22, 105-122.

McEwen, B. S. (2002). Sex, stress and the hippocampus: Allostasis, allostatic load and the aging process. Neurobiological Aging, 23, 921-939.

McEwen, B. S. (2005). Glucocorticoids, depression, and mood disorders: Structural remodeling in the brain. Metabolism, 54, 20-23.

Merino, J. J., Cordero, M. I., \& Sandi, C. (2000). Regulation of hippocampal cell adhesion molecules NCAM and L1 by contextual fear conditioning is dependent upon time and stressor intensity. European Journal of Neuroscience, 12 3283-3290.

Micheau, J., Destrade, C., \& Soumireu-Mourat, B. (1984). Time-dependent effects of posttraining intrahippocampal injections of corticosterone on retention of appetitive learning tasks in mice. European Journal of Pharmacology, 106, 39-46.

Morris, R. G. (2006). Elements of a neurobiological theory of hippocampal function: The role of synaptic plasticity, synaptic tagging and schemas. European Journal of Neuroscience, 23, 2829-2846.

Morris, R. G., Moser, E. I., Riedel, G., Martin, S. J., Sandin, J., Day, M., et al. (2003) Elements of a neurobiological theory of the hippocampus: The role of activitydependent synaptic plasticity in memory. Philosophical Transactions of the Roya Society of London. B. Biological Sciences, 358, 773-786.

Muller, D., Djebbara-Hannas, Z., Jourdain, P., Vutskits, L., Durbec, P., Rougon, G., et al (2000). Brain-derived neurotrophic factor restores long-term potentiation in polysialic acid-neural cell adhesion molecule-deficient hippocampus. Proceedings of the National Academy of Sciences of the United States of America, 97, 4315-4320.

Muller, D., Mendez, P., De Roo, M., Klauser, P., Steen, S., Poglia, L. (in press). Role of NCAM in Spine Dynamics and Synaptogenesis. Neurochemical Research.

Muller, D., Wang, C., Skibo, G., Toni, N., Cremer, H., Calaora, V., et al. (1996). PSANCAM is required for activity-induced synaptic plasticity. Neuron, 17, 413-422.

Murphy, K. J., O'Connell, A. W., \& Regan, C. M. (1996). Repetitive and transient increases in hippocampal neural cell adhesion molecule polysialylation state following multitrial spatial training. Journal of Neurochemistry, 67, 1268-1274.

Murphy, K. J., \& Regan, C. M. (1998). Contributions of cell adhesion molecules to altered synaptic weightings during memory consolidation. Neurobiology of Learning and Memory, 70, 73-81.

Nakayama, J., Fukuda, M. N., Fredette, B., Ranscht, B., \& Fukuda, M. (1995). Expression cloning of a human polysialyltransferase that forms the polysialylated neural cell adhesion molecule present in embryonic brain. Proceedings of the National Academy of Sciences of the United States of America, 92, 7031-7035.

Neiiendam, J. L., Kohler, L. B., Christensen, C., Li, S., Pedersen, M. V., Ditlevsen, D. K., et al. (2004). An NCAM-derived FGF-receptor agonist, the FGL-peptide, induces neurite outgrowth and neuronal survival in primary rat neurons. Journal of Neurochemistry, 91, 920-935.

O'Connell, A. W., Fox, G. B., Barry, T., Murphy, K. J., Fichera, G., Foley, A. G., et al (1997). Spatial learning activates neural cell adhesion molecule polysialylation in a corticohippocampal pathway within the medial temporal lobe. Journal of Neurochemistry, 68, 2538-2546.

Oitzl, M. S., \& de Kloet, E. R. (1992). Selective corticosteroid antagonists modulate specific aspects of spatial orientation learning. Behavioral Neurosciences, 106, 62-71.
Park, C. R., Zoladz, P. R., Conrad, C. D., Fleshner, M., \& Diamond, D. M. (2008). Acute predator stress impairs the consolidation and retrieval of hippocampusdependent memory in male and female rats. Learning $\mathcal{E}$ Memory, 15, 271-280.

Pham, K., Nacher, J., Hof, P. R., \& McEwen, B. S. (2003). Repeated restraint stress suppresses neurogenesis and induces biphasic PSA-NCAM expression in the adult rat dentate gyrus. European Journal of Neuroscience, 17, 879-886.

Plappert, C. F., Schachner, M., \& Pilz, P. K. (2006). Neural cell adhesion molecule (NCAM-/-) null mice show impaired sensitization of the startle response. Genes, Brain, and Behaviour, 5, 46-52.

Prybylowski, K., Chang, K., Sans, N., Kan, L., Vicini, S., \& Wenthold, R. J. (2005). The synaptic localization of NR2B-containing NMDA receptors is controlled by interactions with PDZ proteins and AP-2. Neuron, 47, 845-857.

Radulovic, J., Ruhmann, A., Liepold, T., \& Spiess, J. (1999). Modulation of learning and anxiety by corticotropin-releasing factor (CRF) and stress: Differential roles of CRF receptors 1 and 2. Journal of Neuroscience, 19, 5016-5025.

Revest, J. M., Di Blasi, F., Kitchener, P., Rouge-Pont, F., Desmedt, A., Turiault, M., et al. (2005). The MAPK pathway and Egr-1 mediate stress-related behavioral effects of glucocorticoids. Nature Neuroscience, 8, 664-672.

Rodriguez Manzanares, P. A., Isoardi, N. A., Carrer, H. F., \& Molina, V. A. (2005). Previous stress facilitates fear memory, attenuates GABAergic inhibition, and increases synaptic plasticity in the rat basolateral amygdala. Journal of Neuroscience, 25, 8725-8734.

Ronn, L. C., Bock, E., Linnemann, D., \& Jahnsen, H. (1995). NCAM-antibodies modulate induction of long-term potentiation in rat hippocampal CA1. Brain Research, 677, 145-151.

Roozendaal, B. (2002). Stress and memory: Opposing effects of glucocorticoids on memory consolidation and memory retrieval. Neurobiology of Learning and Memory, 78, 578-595.

Roozendaal, B. (2003). Systems mediating acute glucocorticoid effects on memory consolidation and retrieval. Prog Neuropsychopharmacol Biological Psychiatry, 27, 1213-1223.

Roozendaal, B., Barsegyan, A., \& Lee, S. (2008). Adrenal stress hormones, amygdala activation, and memory for emotionally arousing experiences. Progress in Brain Research, 167, 79-97.

Roozendaal, B., Bohus, B., \& McGaugh, J. L. (1996). Dose-dependent suppression of adrenocortical activity with metyrapone: Effects on emotion and memory. Psychoneuroendocrinology, 21, 681-693.

Roozendaal, B., Griffith, Q. K., Buranday, J., De Quervain, D. J., \& McGaugh, J. L. (2003). The hippocampus mediates glucocorticoid-induced impairment of spatial memory retrieval: Dependence on the basolateral amygdala Proceedings of the National Academy of Sciences of the United States of America, $100,1328-1333$

Roozendaal, B., Hahn, E. L., Nathan, S. V., de Quervain, D. J., \& McGaugh, J. L. (2004) Glucocorticoid effects on memory retrieval require concurrent noradrenergic activity in the hippocampus and basolateral amygdala. Journal of Neuroscience, 24, 8161-8169.

Roozendaal, B., \& McGaugh, J. L. (1996). Amygdaloid nuclei lesions differentially affect glucocorticoid-induced memory enhancement in an inhibitory avoidance task. Neurobiology of Learning and Memory, 65, 1-8.

Roozendaal, B., \& McGaugh, J. L. (1997). Glucocorticoid receptor agonist and antagonist administration into the basolateral but not central amygdala modulates memory storage. Neurobiology of Learning and Memory, 67, 176-179.

Roozendaal, B., Williams, C. L., \& McGaugh, J. L. (1999). Glucocorticoid receptor activation in the rat nucleus of the solitary tract facilitates memory consolidation: Involvement of the basolateral amygdala. European Journal of Neuroscience, 11, 1317-1323.

Rougon, G., \& Hobert, O. (2003). New insights into the diversity and function of neuronal immunoglobulin superfamily molecules. Annu Reviews of Neuroscience, 26, 207-238.

Rutishauser, U. (1998). Polysialic acid at the cell surface: Biophysics in service of cell interactions and tissue plasticity. Journal of Cellular Biochemistry, 70, 304-312.

Rutishauser, U. (2008). Polysialic acid in the plasticity of the developing and adult vertebrate nervous system. Nature Reviews Neuroscience, 9, 26-35.

Sadoul, R., Hirn, M., Deagostini-Bazin, H., Rougon, G., \& Goridis, C. (1983). Adult and embryonic mouse neural cell adhesion molecules have different binding properties. Nature, 304, 347-349.

Sandi, C. (1998). The role and mechanisms of action of glucocorticoid involvement in memory storage. Neural Plasticity, 6, 41-52.

Sandi, C. (2004). Stress, cognitive impairment and cell adhesion molecules. Nature Reviews Neuroscience, 5, 917-930.

Sandi, C., \& Bisaz, R. (2007). A model for the involvement of neural cell adhesion molecules in stress-related mood disorders. Neuroendocrinology, 85, 158-176.

Sandi, C., Cordero, M. I., Merino, J. J., Kruyt, N. D., Regan, C. M., \& Murphy, K. J. (2004). Neurobiological and endocrine correlates of individual differences in spatial learning ability. Learning \& Memory, 11, 244-252.

Sandi, C., \& Loscertales, M. (1999). Opposite effects on NCAM expression in the rat frontal cortex induced by acute vs. chronic corticosterone treatments. Brain Research, 828, 127-134.

Sandi, C., Loscertales, M., \& Guaza, C. (1997). Experience-dependent facilitating effect of corticosterone on spatial memory formation in the water maze. European Journal of Neuroscience, 9, 637-642.

Sandi, C., Merino, J. J., Cordero, M. I., Kruyt, N. D., Murphy, K. J., \& Regan, C. M. (2003). Modulation of hippocampal NCAM polysialylation and spatial memory consolidation by fear conditioning. Biological Psychiatry, 54, 599-607.

Sandi, C., \& Pinelo-Nava, M. T. (2007). Stress and memory: Behavioral effects and neurobiological mechanisms. Neural Plasticity, 2007, 78970. 
Sandi, C., Rose, S. P., Mileusnic, R., \& Lancashire, C. (1995). Corticosterone facilitates long-term memory formation via enhanced glycoprotein synthesis. Neuroscience, 69, 1087-1093.

Sandi, C., Woodson, J. C., Haynes, V. F., Park, C. R., Touyarot, K., Lopez-Fernandez, M. A., et al. (2005). Acute stress-induced impairment of spatial memory is associated with decreased expression of neural cell adhesion molecule in the hippocampus and prefrontal cortex. Biological Psychiatry, 57, 856-864.

Schachner, M. (1997). Neural recognition molecules and synaptic plasticity. Current Opinion in Cell Biology, 9, 627-634.

Scheidegger, E. P., Sternberg, L. R., Roth, J., \& Lowe, J. B. (1995). A human STX cDNA confers polysialic acid expression in mammalian cells. Journal of Biological Chemistry, 270, 22685-22688.

Scholey, A. B., Rose, S. P., Zamani, M. R., Bock, E., \& Schachner, M. (1993). A role for the neural cell adhesion molecule in a late, consolidating phase of glycoprotein synthesis six hours following passive avoidance training of the young chick. Neuroscience, 55, 499-509.

Schummers, J., Yu, H., \& Sur, M. (2008). Tuned responses of astrocytes and their influence on hemodynamic signals in the visual cortex. Science, 320, 1638-1643.

Seki, T., \& Arai, Y. (1993). Highly polysialylated neural cell adhesion molecule (NCAM-H) is expressed by newly generated granule cells in the dentate gyrus of the adult rat. Journal of Neuroscience, 13, 2351-2358.

Seki, T., \& Arai, Y. (1999). Different polysialic acid-neural cell adhesion molecule expression patterns in distinct types of mossy fiber boutons in the adult hippocampus. Journal of Comparative Neurology, 410, 115-125.

Senkov, O., Sun, M., Weinhold, B., Gerardy-Schahn, R., Schachner, M., \& Dityatev, A. (2006). Polysialylated neural cell adhesion molecule is involved in induction of long-term potentiation and memory acquisition and consolidation in a fearconditioning paradigm. Journal of Neuroscience, 26, 10888-10898.

Servatius, R. J., \& Shors, T. J. (1994). Exposure to inescapable stress persistently facilitates associative and nonassociative learning in rats. Behavioral Neurosciences, 108, 1101-1106.

Shors, T. J. (2004). Learning during stressful times. Learning \& Memory, 11, 137-144.

Shors, T. J., Chua, C., \& Falduto, J. (2001). Sex differences and opposite effects of stress on dendritic spine density in the male versus female hippocampus. Journal of Neuroscience, 21, 6292-6297.

Shors, T. J., \& Mathew, P. R. (1998). NMDA receptor antagonism in the lateral/ basolateral but not central nucleus of the amygdala prevents the induction of facilitated learning in response to stress. Learning \& Memory, 5, 220-230.

Shors, T. J., \& Servatius, R. J. (1997). The contribution of stressor intensity, duration, and context to the stress-induced facilitation of associative learning. Neurobiology of Learning and Memory, 68, 92-96.

Shors, T. J., Weiss, C., \& Thompson, R. F. (1992). Stress-induced facilitation of classical conditioning. Science, 257, 537-539.
Stork, O., Welzl, H., Cremer, H., \& Schachner, M. (1997). Increased intermale aggression and neuroendocrine response in mice deficient for the neural cell adhesion molecule (NCAM). European Journal of Neuroscience, 9, 1117-1125.

Stork, O., Welzl, H., Wolfer, D., Schuster, T., Mantei, N., Stork, S., et al. (2000). Recovery of emotional behaviour in neural cell adhesion molecule (NCAM) null mutant mice through transgenic expression of NCAM180. European Journal of Neuroscience, 12, 3291-3306.

Stork, O., Welzl, H., Wotjak, C. T., Hoyer, D., Delling, M., Cremer, H., et al. (1999). Anxiety and increased 5-HT1A receptor response in NCAM null mutant mice. Journal of Neurobiology, 40, 343-355.

Tomasiewicz, H., Ono, K., Yee, D., Thompson, C., Goridis, C., Rutishauser, U., et al (1993). Genetic deletion of a neural cell adhesion molecule variant (N-CAM180 ) produces distinct defects in the central nervous system. Neuron, 11 1163-1174.

Touyarot, K., Venero, C., \& Sandi, C. (2004). Spatial learning impairment induced by chronic stress is related to individual differences in novelty reactivity: Search for neurobiological correlates. Psychoneuroendocrinology, 29, 290-305.

Venero, C., Herrero, A. I., Touyarot, K., Cambon, K., Lopez-Fernandez, M. A., Berezin, V., et al. (2006). Hippocampal up-regulation of NCAM expression and polysialylation plays a key role on spatial memory. European Journal of Neuroscience, 23, 1585-1595.

Venero, C., Tilling, T., Hermans-Borgmeyer, I., Herrero, A. I., Schachner, M., \& Sandi, C. (2004). Water maze learning and forebrain mRNA expression of the neural cell adhesion molecule L1. Journal of Neuroscience Research, 75, 172-181.

Waddell, J., Bangasser, D. A., \& Shors, T. J. (2008). The basolateral nucleus of the amygdala is necessary to induce the opposing effects of stressful experience on learning in males and females. Journal of Neuroscience, 28, 5290-5294.

Walmod, P. S., Kolkova, K., Berezin, V., \& Bock, E. (2004). Zippers make signals: NCAM-mediated molecular interactions and signal transduction. Neurochemical Research, 29, 2015-2035.

Weiss, C., Sametsky, E., Sasse, A., Spiess, J., \& Disterhoft, J. F. (2005). Acute stress facilitates trace eyeblink conditioning in $\mathrm{C} 57 \mathrm{BL} / 6$ male mice and increases the excitability of their CA1 pyramidal neurons. Learning E Memory, 12, 138-143.

Wiedenmayer, C. P. (2004). Adaptations or pathologies? Long-term changes in brain and behavior after a single exposure to severe threat. Neuroscience and Biobehavioral Reviews, 28, 1-12.

Wiegert, O., Joels, M., \& Krugers, H. J. (2008). Corticosteroid hormones, synaptic strength and emotional memories: Corticosteroid modulation of memory - a cellular and molecular perspective. Progress in Brain Research, 167, 269-271.

Woodson, J. C., Macintosh, D., Fleshner, M., \& Diamond, D. M. (2003). Emotioninduced amnesia in rats: Working memory-specific impairment, corticosterone-memory correlation, and fear versus arousal effects on memory. Learning \&' Memory, 10, 326-336. 